\title{
Inhibition of Skp2 suppresses the proliferation and invasion of osteosarcoma cells
}

\author{
LU DING ${ }^{1,2^{*}}$, RONG LI $^{3 *}$, XIAOPING HAN ${ }^{2 *}$, YUBO ZHOU $^{4}, \mathrm{HUA} \mathrm{ZHANG}^{2}$, \\ YONG CUI ${ }^{2}$, WU WANG ${ }^{2}$ and JINGPING BAI ${ }^{1}$ \\ ${ }^{1}$ Department of Orthopedics, Tumor Hospital Affiliated to Xinjiang Medical University; \\ ${ }^{2}$ Department of Orthopedics, Fifth Affiliated Hospital, Xinjiang Medical University; \\ ${ }^{3}$ Department of Maternal, Child and Adolescent Health, College of Public Health, \\ Xinjiang Medical University Xinshi, Urumqi, Xinjiang 830000; \\ ${ }^{4}$ Department of Orthopedics, Traditional Chinese Medicine Hospital \\ Affiliated to Xinjiang Medical University, Xinshi, \\ Urumqi, Xinjiang, P.R. China
}

Received August 25, 2016; Accepted October 19, 2016

DOI: $10.3892 /$ or.2017.5713

\begin{abstract}
Osteosarcoma (OS) is a common bone tumor that mainly affects children and young adults. S-phase kinase-associated protein 2 (Skp2) has been characterized to play a critical oncogenic role in a variety of human malignancies. However, the biological function of Skp2 in OS remains largely obscure. In the present study, we elucidated the role of Skp2 in cell growth, cell cycle, apoptosis and migration in OS cells. We found that depletion of Skp2 inhibited cell growth in both MG-63 and SW 1353 cells. Moreover, we observed that depletion of Skp2 triggered cell apoptosis in two OS cell lines. Furthermore, downregulation of Skp2 induced cell cycle arrest in the G0/G1 phase in OS cells. Notably, our wound healing assay results revealed that inhibition of Skp2 suppressed cell migration in OS cells. Invariably, our western blot results demonstrated that depletion of Skp2 in OS cells inhibited activation of pAkt and increased p27 expression in OS cells, suggesting that Skp2 exerted its oncogenic function partly through the regulation of Akt and p27. Our findings revealed that targeting Skp2 could be a promising therapeutic strategy for the treatment of OS.
\end{abstract}

Correspondence to: Dr Jingping Bai, Department of Orthopedics, Tumor Hospital Affiliated to Xinjiang Medical University, 789 Suzhou Road, Xinshi, Urumqi, Xinjiang 830000, P.R. China E-mail: baijingpingxj@126.com

*Contributed equally

Key words: osteosarcoma, S-phase kinase-associated protein 2, cell proliferation, invasion, apoptosis

\section{Introduction}

Osteosarcoma(OS) is a common bone cancer that mainly affects children and adolescents $(1,2)$. Although multiple treatments including local control interventions and chemotherapy have improved the survival of patients with OS, the survival rate is still $\sim 60-80 \%$ in OS patients (3). Moreover, the 5-year event-free survival for patients with high grade OS is still less than $50 \%$ (3). Therefore, it is imperative to develop more effective therapeutic strategies for the treatment of OS. It has been demonstrated that genetic and cytogenetic abnormalities are critically involved in the development and progression of OS (4). For example, mutations in tumor suppressors and activation of oncogenes are associated with OS (5). Therefore, it is essential to understand the molecular mechanism of OS tumorigenesis and to validate novel therapeutic targets for OS.

Emerging evidence has revealed that several biological molecules could be effective therapeutic targets for OS. For instance, multiple genes such as Notch, Wnt, nuclear factor- $\kappa \mathrm{B}(\mathrm{NF}-\kappa \mathrm{B}), \mathrm{p} 53$, phosphoinositide 3-kinase (PI3K)/ Akt and mitogen-activated protein kinase (MAPK) are critical in the development of OS (4). Tao et al identified that Notch activation is a driver of osteogenic sarcoma (6). Recent studies have validated that $\mathrm{S}$-phase kinase-associated protein 2 (Skp2) plays an essential role in the development of various human malignancies. Skp2 has been characterized to exhibit its oncogenic function via targeting of its substrates including p27 (7,8), p21 (9), p57 (10) and Forkhead box protein $\mathrm{O} 1$ (FOXO1) $(11,12)$. Engineered mouse models revealed that conditional depletion of Skp2 in mice suppressed tumor growth in T cell lineage (13), B cell lineage (14), bone marrow (15), liver $(16,17)$, breast (18), prostate (19) and skin cancer (20). Consistently, upregulation of Skp2 in mice enhanced tumor growth in lymphoma (21), prostate cancer (19) and breast tumor (18). Importantly, high expression of Skp2 has been observed in a wider spectrum of cancers including lymphomas $(22,23)$, pancreatic cancer $(24)$, breast 
carcinomas (25-29), prostate $(30,31)$ and gastric cancer (32), melanoma (33-35), hepatocarcinoma (36) and nasopharyngeal carcinoma $(37,38)$. Skp2 was also highly expressed and was correlated with relapse, metastasis and survival in OS patients (39). However, the role of Skp2 in OS has not been fully elucidated.

In the present study to explore the role of Skp2 in OS, we depleted Skp2 in MG-63 and SW 1353 cells. Then, we investigated the biological function of Skp2 in cell growth, apoptosis, and in the cell cycle of OS cells after knockdown of Skp2. Moreover, we assessed the effects of Skp2 depletion on OS cell migration. Methodically, we determined whether the downstream targets of Skp2 are involved in the progression of OS. We found that depletion of Skp2 inhibited cell growth, induced apoptosis, arrested the cell cycle and suppressed cell migration in OS cells. Moreover, depletion of Skp2 exerted its function partly through the regulation of Akt and p27 in OS cells. Our findings suggest that targeting Skp2 may be a promising therapeutic strategy for the treatment of OS.

\section{Materials and methods}

Cell culture, reagents and antibodies. The human OS MG-63 and SW 1353 cells (ATCC, Manassas, VA, USA) were cultured at $37^{\circ} \mathrm{C}$ in $5 \% \mathrm{CO}_{2}$ in Dulbecco's modified Eagle's medium (DMEM; Gibco, Carlsbad, CA, USA) supplemented with $10 \%$ fetal bovine serum (FBS). 3-(4,5-Dimethythiazol-2-yl)2,5-diphenyltetrazolium bromide (MTT) was obtained from Sigma-Aldrich (St. Louis, MO, USA). Anti-Akt and anti-pAkt antibodies were obtained from Cell Signaling Technology (Danvers, MA, USA). Antibodies against $\beta$-actin, Skp2 and p27 were purchased from Santa Cruz Biotechnology (Santa Cruz, CA, USA).

Transfection. Cells were seeded into 6-well plates and transfected with control siRNA or Skp2 siRNAs (GenePharma, Shanghai, China) using Lipofectamine 2000 according to the manufacturer's protocol.

MTT assay. Cells were seeded at equal densities into 96-well culture plates. After $24 \mathrm{~h}$, the cells were then treated with Skp2 siRNA for $48 \mathrm{~h}$. An MTT assay was conducted to determine the absorbance at $560 \mathrm{~nm}$ using a Benchmark Microplate Reader (Bio-Rad, Hercules, CA, USA). All values were normalized to those of the control.

Cell cycle analysis. The transfected cells were seeded into $100-\mathrm{mm}$ dishes for $48 \mathrm{~h}$. Then, the cells were fixed in ice-cold 70\% ethanol in phosphate-buffered saline (PBS) for $12 \mathrm{~h}$. The fixed cells were treated with $0.1 \mathrm{mg} / \mathrm{ml}$ RNase A for $20 \mathrm{~min}$. The cells were re-suspended in propidium iodide (PI) $(50 \mu \mathrm{g} / \mathrm{ml})$. Cell cycle distribution was assessed using a FACScan flow cytometer and analyzed.

Apoptosis assay. The transfected cells were cultured into a 6-well plate for $48 \mathrm{~h}$. Then, the cells were harvested and washed with PBS, resuspended in $500 \mu 1$ of binding buffer with $5 \mu \mathrm{l}$ of PI and $5 \mu \mathrm{l}$ of FITC-conjugated anti-Annexin V antibody. Apoptosis was assessed by a FACSCalibur flow cytometer.
Real-time RT-PCR analysis. Total RNA from transfected cells was isolated using TRIzol and reversed-transcribed into cDNA by RevertAid First Strand cDNA Synthesis kit according to the manufacturer's protocol. The primers used in the PCR reactions were: Skp2 forward, 5'-GCT GCT AAA GGT CTC TGG TGT-3' and reverse, 5'-AGG CTT AGA TTC TGC AAC TTG-3'; GAPDH forward, 5'-ACC CAG AAG ACT GTG GAT GG-3' and reverse, 5'-CAG TGA GCT TCC CGT TCA G-3'. The expression of GAPDH was used as an internal control.

Western blot analysis. Cells were lysed in lysis buffer and protein concentrations were detected by Brandford assay reagent. Equal amounts of proteins were resolved on SDS-PAGE, and then transferred to membranes. The membranes were immunoblotted with primary antibodies including Skp2, Akt, phosphor-Akt-Ser473, p27 and $\beta$-actin, followed by secondary antibodies conjugated with horseradish peroxidase. Then, the bands were revealed using an enzyme-linked chemiluminescence (ECL) detection kit assay.

Wound healing assay. Cells were cultured in 6-well plates and grown to confluency. When cells converged to $\sim 100 \%$, monolayers of cells were scratched with $200 \mu$ yellow pipette tips and washed with PBS. The scratched area was photographed with a microscope at 0 and $20 \mathrm{~h}$, respectively.

Transwell invasion assay. An invasion assay was carried out using BD BioCoat Matrigel invasion chambers. Briefly, tranfected cells were seeded in DMEM without serum in the upper chamber. DMEM containing $10 \%$ FBS was added to the lower chamber. After overnight incubation, the non-invading cells were removed. The cells that had invaded through the Matrigel matrix membrane were stained with $4 \mu \mathrm{g} / \mathrm{ml}$ calcein AM in Hanks' buffered saline at $37^{\circ} \mathrm{C}$ for $1 \mathrm{~h}$. The fluorescence of the invaded cells was read on Ultra Multifunctional Microplate Reader (Tecan, Durham, NC, USA) at excitation/emission wavelengths of 530/590 nm. Invasiveness was assessed by calculating the invading cells with a microscope.

Statistical analysis. The data are expressed as the mean \pm SD. A Student's t-test was performed to evaluate statistical significance between the Skp2-siRNA transfection group and the NC-siRNA treated group. The level of significance was considered as $\mathrm{P}<0.05$.

\section{Results}

Skp2 expression is inhibited by its siRNAs in OS cells. To determine whether Skp2 is involved in the regulation of cell proliferation in OS cells, we depleted Skp2 using its specific siRNAs in both MG-63 and SW 1353 cells. Real-time reverse transcription-polymerase chain reaction (RT-PCR) and western blot analysis were applied for the detection of the efficacy of multiple Skp2 siRNAs on inhibition of Skp2 in OS cells. The results from RT-PCR revealed that Skp2 siRNAs significantly downregulated Skp2 mRNA levels in both MG-63 and SW 1353 cells (Fig. 1A). Consistently, our western 
A

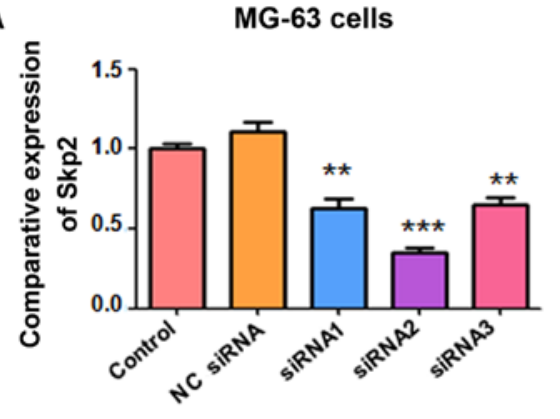

B
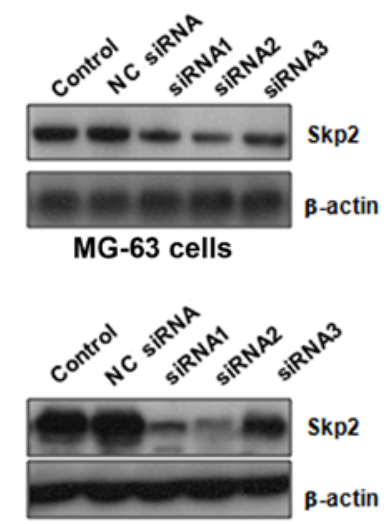

SW 1353 cells
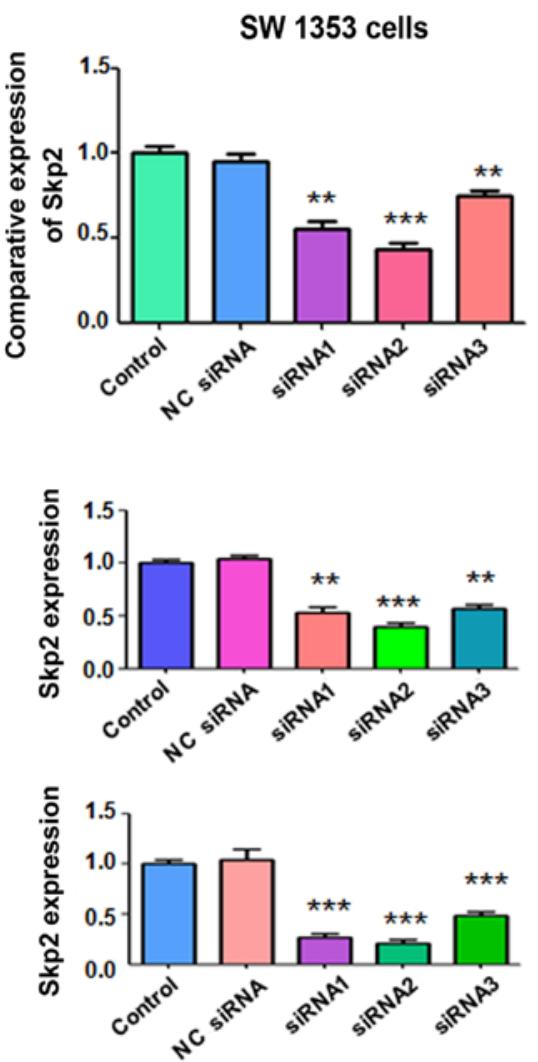
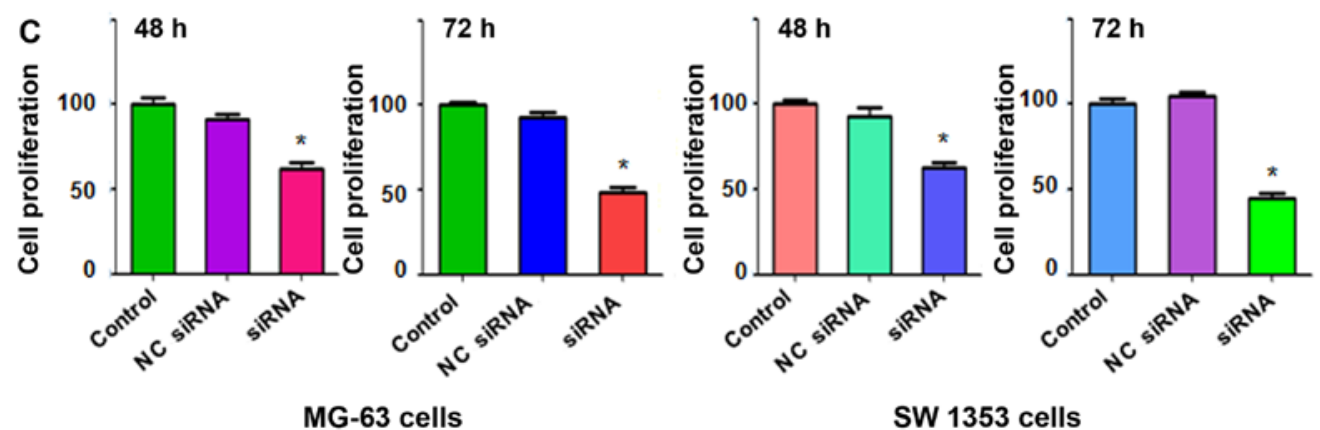

SW 1353 cells

Figure 1. Depletion of Skp2 inhibits cell proliferation. (A) Real-time RT-PCR was performed to assess the efficacy of Skp2-siRNA in OS cell lines. Control, without any treatment group; NC siRNA, non-specific siRNA; siRNA, Skp2 siRNA; ${ }^{* *} \mathrm{P}<0.01,{ }^{* * *} \mathrm{P}<0.001 \mathrm{vs.}$ the control or NC siRNA. (B) The left panel displays the western blot analysis results of Skp2 in OS cell lines transfected with different Skp2 siRNAs. The right panel displays the quantitation of results from the left panel; ${ }^{* *} \mathrm{P}<0.01,{ }^{* * *} \mathrm{P}<0.001$ vs. the control or NC siRNA. (C) An MTT assay was performed in OS cell lines after treatment with Skp2 siRNA for 48 and $72 \mathrm{~h} ;{ }^{*} \mathrm{P}<0.05$ vs. the control or NC siRNA. Skp2, S-phase kinase-associated protein 2.

blot analysis demonstrated that Skp2 siRNAs markedly inhibited the expression of Skp2 in both OS cell lines (Fig. 1B). In the following experiments, Skp2 siRNA2 was used to deplete Skp2 expression in the two OS cell lines.

Depletion of Skp2 inhibits cell proliferation in OS cells. It has been demonstrated that downregulation of Skp2 suppressed cell proliferation in human cancer cells. To determine whether Skp2 regulates cell proliferation in OS cells, an MTT assay was performed to assess cell proliferation in OS cells transfected with Skp2 siRNA. We found that depletion of Skp2 significantly inhibited cell proliferation in MG-63 cells compared with the control group (Fig. 1C). Similarly, Skp2 siRNA treatment led to inhibition of cell proliferation in SW 1353 cells (Fig. 1C). Our findings revealed that depletion of Skp2 suppressed cell proliferation in OS cells.
Depletion of Skp2 triggers apoptosis in OS cells. Next, we used an Annexin V-FITC/PI apoptosis detection kit to assess apoptosis in OS cells after Skp2-siRNA transfection. We found that depletion of Skp2 induced apoptosis in both MG-63 and SW 1353 cells (Fig. 2A and B). The percentage of apoptotic cells increased from $13.43 \%$ in the control siRNA-treated group to $30.6 \%$ in the Skp2 siRNA-treated group in the SW 1353 cells (Fig. 2B). We also observed that downregulation of Skp2 enhanced apoptosis in the MG-63 cells (Fig. 2A). These data indicated that depletion of Skp2 led to increased apoptosis, which contributed to cell growth inhibition in both OS cell lines.

Depletion of Skp2 induces cell cycle arrest in OS cells. To explore whether Skp2 regulates cell cycle progression, PI staining and flow cytometry assays were conducted in OS cells treated with Skp2 siRNA. We found a typical 
A

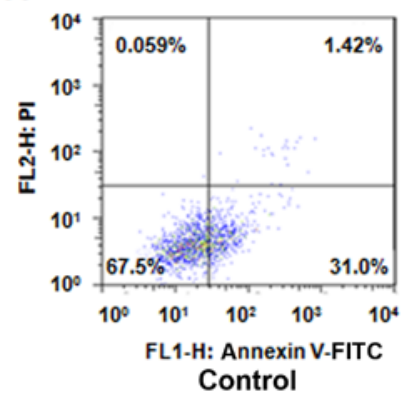

B

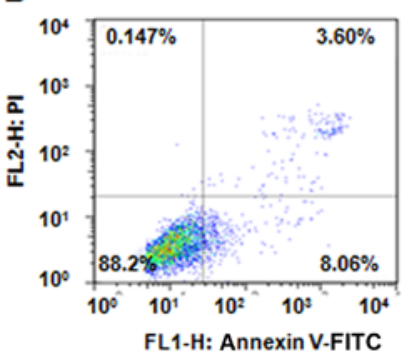

Control

C
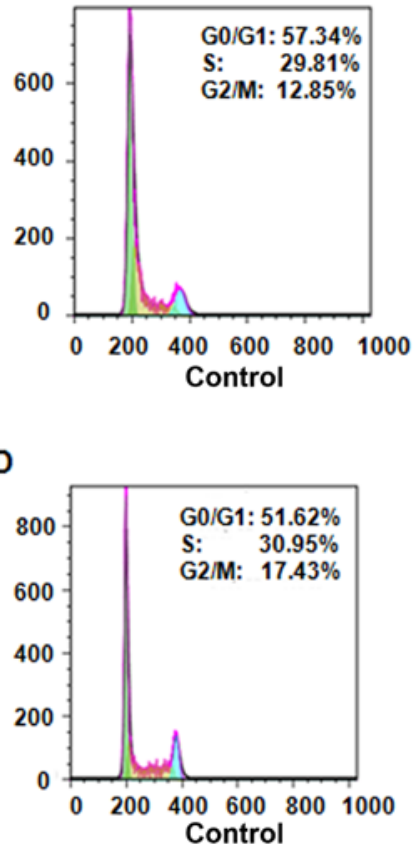
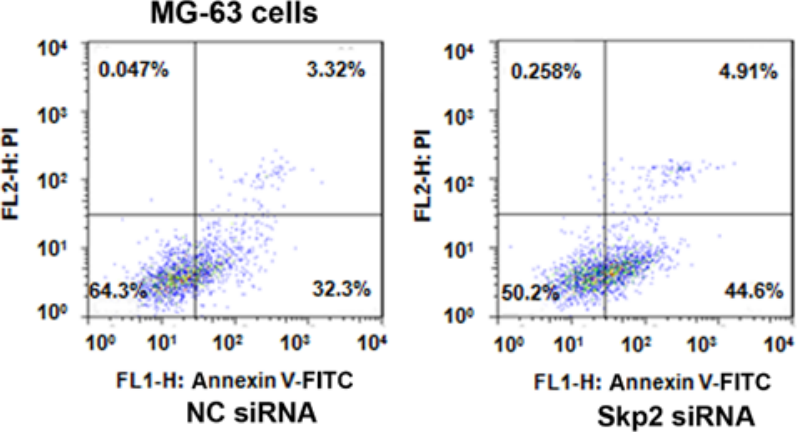

SW 1353 cells

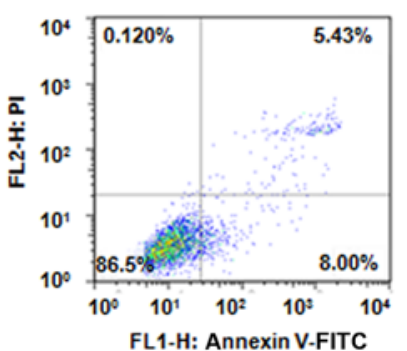

NC SIRNA
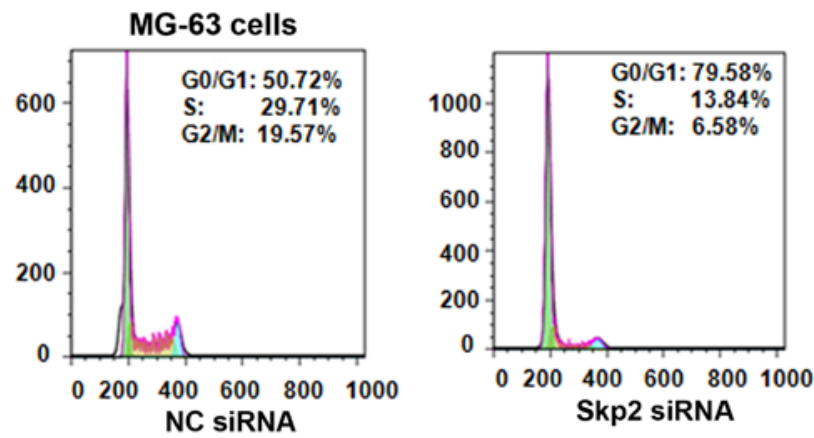

Skp2 siRNA

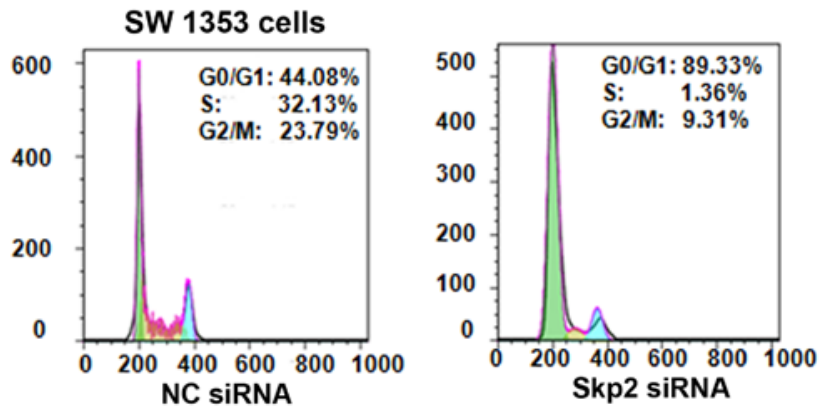

Figure 2. Depletion of Skp2 induces apoptosis and cell cycle arrest. (A and B) Cell apoptosis in OS cells treated with Skp2 siRNA was assessed using flow cytometry. Control, without any treatment group; NC siRNA, non-specific siRNA; siRNA, Skp2 siRNA. (C and D) FACS was conducted to detect the cell cycle in OS cells treated with Skp2 siRNA for 48 and $72 \mathrm{~h}$. Skp2, S-phase kinase-associated protein 2.

G0/G1 arrest pattern in both Skp2 siRNA-treated OS cell lines (Fig. 2C and D). The G0/G1 phase fraction increased from $50.72 \%$ in the control siRNA-treated cells to $79.58 \%$ in the Skp2 siRNA-treated MG-63 cells (Fig. 2C). Similarly, G0/G1 cell cycle arrest was found in the Skp2 siRNA-treated SW 1353 cells (Fig. 2D). These results demonstrated that depletion of Skp2 induced G0/G1 arrest in OS cells.

Depletion of Skp2 suppresses cell migration and invasion in OS cells. To explore whether depletion of Skp2 suppresses the motility of OS cells, wound healing assays were conducted to assess the migration of OS cells following Skp2-siRNA transfection. Our results from the wound healing assays demonstrated that inhibition of Skp2 significantly decreased cell migration in both OS cell lines (Fig. 3). To further validate this finding, migration and invasion assays were performed to determine the cell migratory and invasive activities of OS cells treated with Skp2 siRNA using Transwell chamber assays. We observed that downregulation of Skp2 markedly inhibited the migration and invasion (Fig. 4) in both OS cell 


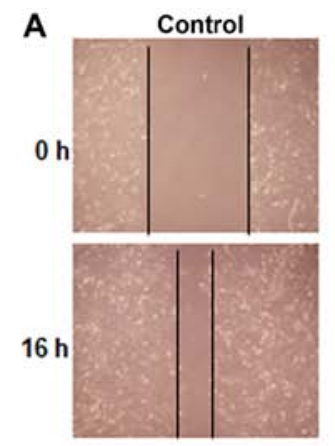

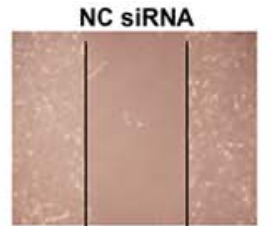
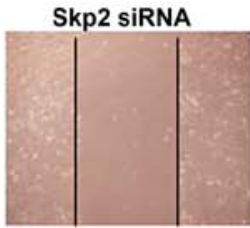

B
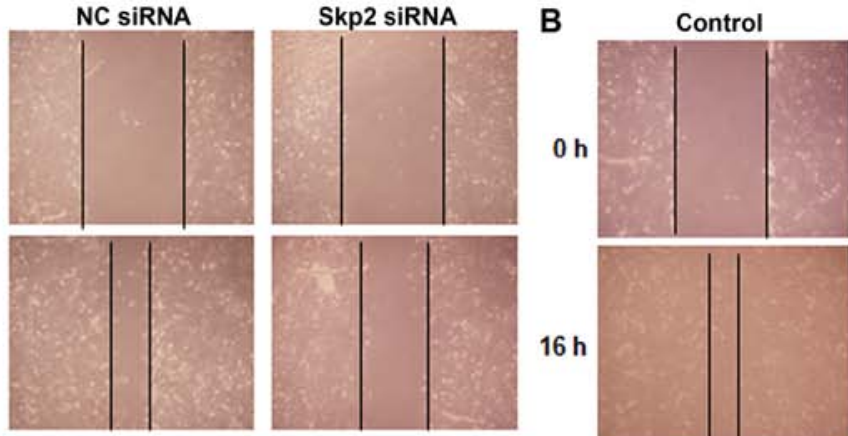

MG-63 cells

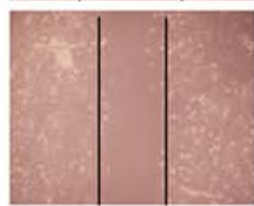

$16 \mathrm{~h}$

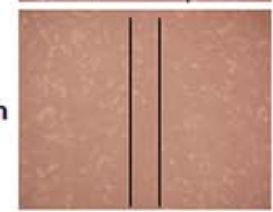

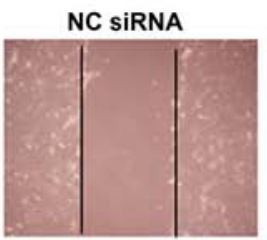

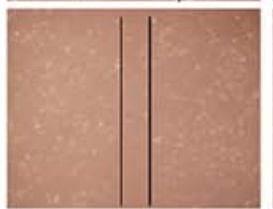

SW 1353 cells
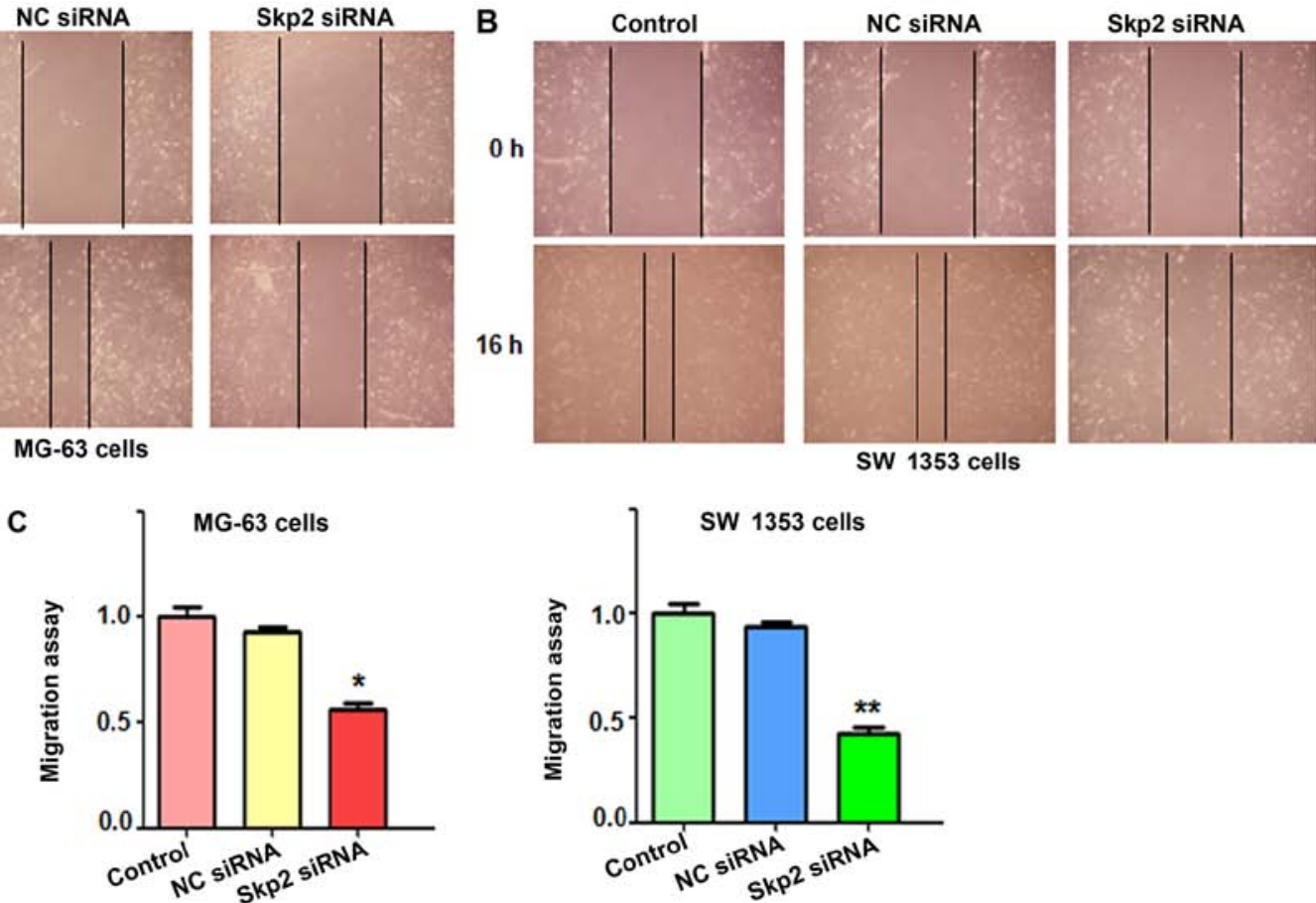

Figure 3. Depletion of Skp2 suppresses the motility activity in OS cells. (A and B) Wound healing assays were used to detect the migratory potential in (A) MG-63 and (B) SW 1353 cells after Skp2-siRNA treatments. Control, without any treatment group; NC siRNA, non-specific siRNA. (C) Quantitative results are illustrated for $\mathrm{A}$ and $\mathrm{B} ;{ }^{*} \mathrm{P}<0.05,{ }^{* *} \mathrm{P}<0.01$ vs. the NC siRNA. Skp2, S-phase kinase-associated protein 2.

A

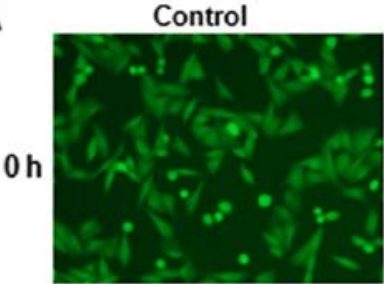

$16 \mathrm{~h}$

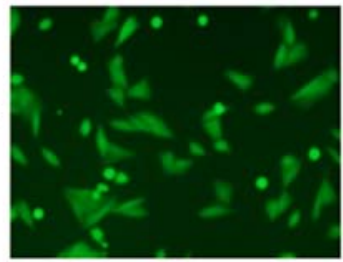

B
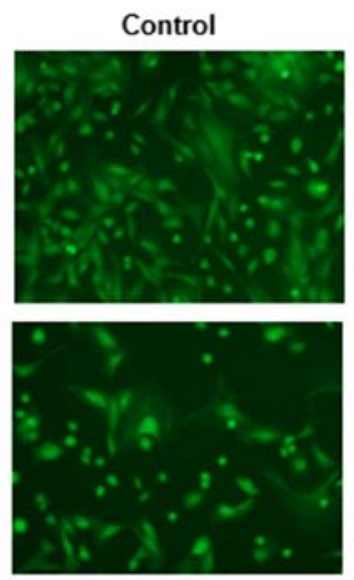

NC siRNA
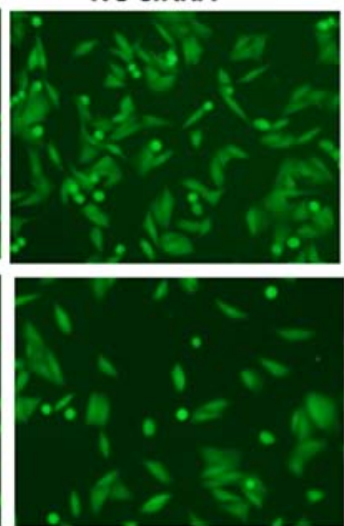

MG-63 cells
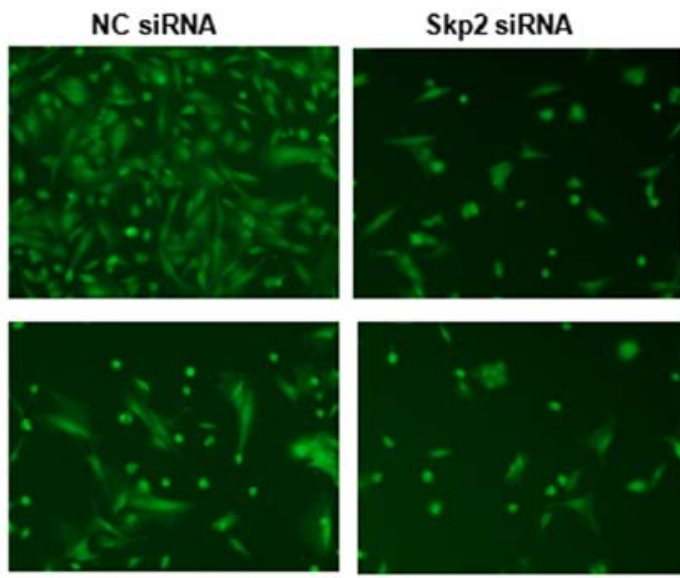

SW 1353 cells
Migration
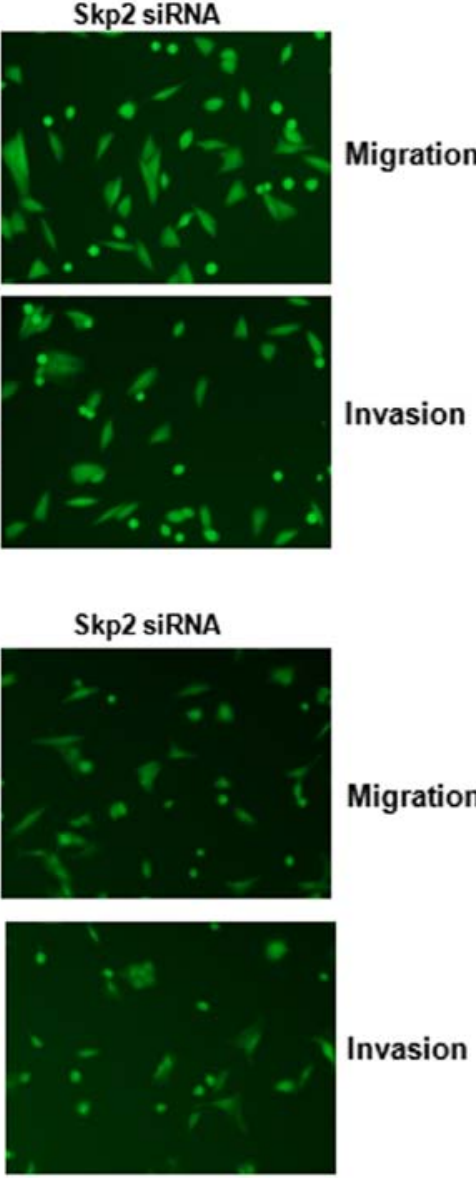

Figure 4. Depletion of Skp2 inhibits migration and invasion in OS cells. (A and B) Migration and invasion assays were used to assess the migratory capacity in (A) MG-63 and (B) SW 1353 cells treated with Skp2 siRNA. Control, without any treatment group; NC siRNA, non-specific siRNA. Skp2, S-phase kinase-associated protein 2 . 
A
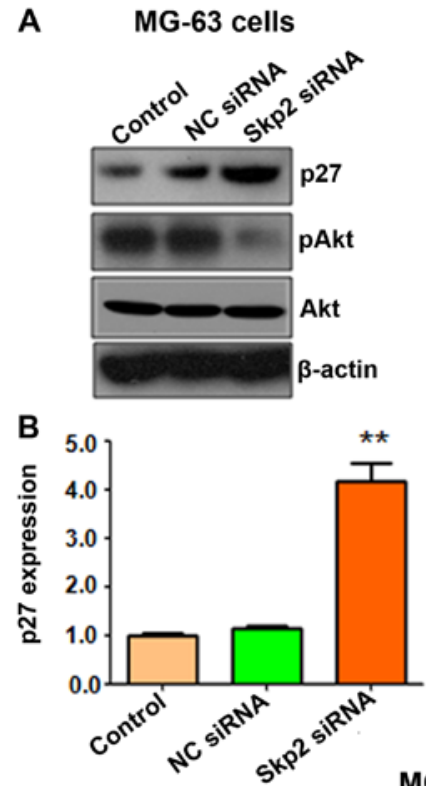

SW 1353 cells
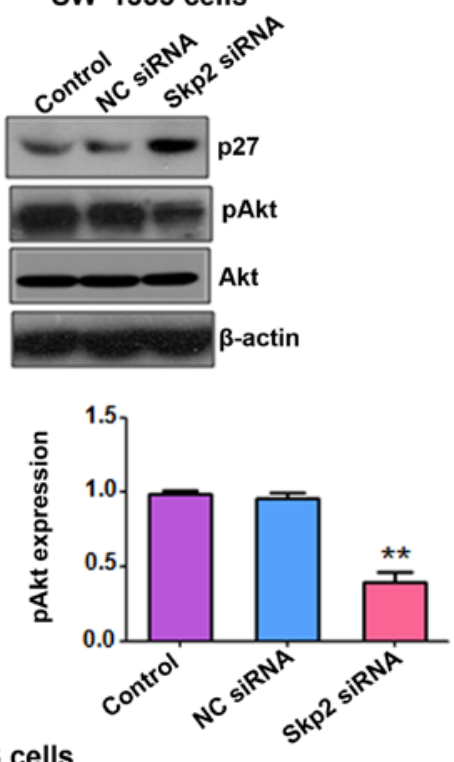
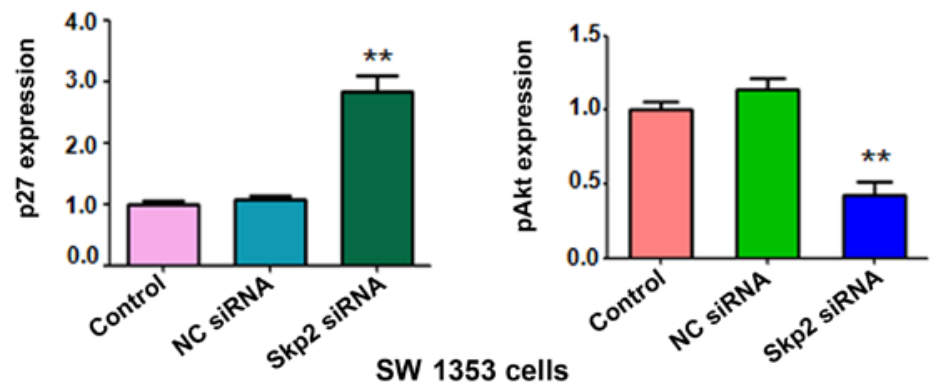

Figure 5. Depletion of Skp2 increases the expression of p27 and decreases the expression pAkt. (A) Western blot analysis was conducted to assess the expression of p27 and pAkt in OS cells transfected with Skp2 siRNA. Control, without any treatment group; NC siRNA, non-specific siRNA. (B) Quantitative results are illustrated for panel $\mathrm{A} ;{ }^{* *} \mathrm{P}<0.01$ vs. the NC siRNA. Skp2, S-phase kinase-associated protein 2.

lines. Altogether, depletion of Skp2 may inhibit motility in OS cells.

Depletion of Skp2 increases the expression level of p27, but decreases the expression level of pAkt in OS cells. It has been demonstrated that $S \mathrm{kp} 2$ regulates the levels of p27 and pAkt, two key targets of Skp2, in several types of human cancers. To further determine whether depletion of Skp2 regulates the expression of p27 and pAkt in OS cells, we assessed the levels of these two genes in the Skp2 siRNA-treated OS cell lines. Our western blot analysis data revealed that downregulation of Skp2 increased p27 expression in both OS cell lines (Fig. 5). Furthermore, depletion of Skp2 decreased the expression of pAkt in OS cells, but not the total level of Akt (Fig. 5). These findings revealed that Skp2 suppressed the expression level of pAkt, but increased the expression of p27 in OS cells.

\section{Discussion}

Various studies have discovered that Skp2 plays an important role in tumorigenesis in a variety of human types of cancer $(40,41)$. However, the function of Skp2 in OS remains largely obscure. Indirect evidence has indicated the function of Skp2 in OS cells. For example, the depletion of Forkhead box M1 (FoxM1) inhibited cell growth in human OS U2OS cells due to dysreguation of Skp2 and Cks1, leading to a mitotic block and accumulated levels of p21 and p27 (42). A previous study indicated that FoxM1 regulated the transcription of cell cycle genes including genes encoding the SCF (Skp2-Cks1) ubiquitin ligase complex (42). Another study demonstrated that inhibition of the Notch pathway by $\gamma$-secretase inhibitor suppressed the growth of OS in vitro and in vivo due to a decrease in the expression of accelerators of the cell cycle such as Skp2, cyclin D1, and cyclin E1 and E2 (43). Similarly, inhibition of smoothened, a key molecule in the Hedgehog pathway, slowed the growth of OS cells via the suppression of Skp2 and cyclin D1 and E1, but upregulation of p21 (44). In line with this, knockdown of Gli2, a key mediator of the Hedgehog pathway, prevented OS growth and anchorage-independent growth, and promoted G1 phase arrest through inhibition of Skp2 and cyclin D1 (45). In the present study, depletion of Skp2 in OS cells inhibited cell growth, arrested the G1 cell cycle, triggered cell apoptosis, and suppressed cell migration. This is direct evidence validating the biological function of Skp2 in OS cells. Our findings demonstrated that inactivation of Skp2 could be a useful approach for the treatment of OS patients.

Accumulated evidence has revealed that Akt directly binds to Skp2 and subsequently enhances the translocation of Skp2 from the nucleus to the cytoplasm, leading to activation of Skp2 function $(46,47)$. Notably, one research 
group reported that Akt could promote $\mathrm{Skp} 2$ translocation to the cytoplasm $(12,48)$. A recent study revealed that Skp2 stimulated Akt activation in human breast cancer cells (49). In line with this finding, our results revealed that depletion of Skp2 inhibited the activation of pAkt in OS cells. This result demonstrated that $\mathrm{Skp} 2$ exerted its oncogenic function partly through the Akt pathway in OS cells. Further detailed investigations are warranted to determine how $\mathrm{Skp} 2$ regulates Akt activation in OS cells.

Since inhibition of $\mathrm{Skp} 2$ represents an effective therapeutic approach for patients with OS, it is critical to discover and develop Skp2 inhibitors. To this end, several Skp2 inhibitors have been developed. For instance, 5-bromo-8-toluylsulfonamidoquinoline-1 inhibited the interaction of Skp2 with cyclin-dependent kinase regulatory subunit 1 (Cks1), leading to the inhibition of cell growth in lung cancer cells (50). Another compound M1 targeted the p300-binding site of Skp2 and disrupted the Skp2/p300 interaction, leading to apoptosis and cell death in cancer cells (51). Arsenic trioxide exhibited its antitumor activity via suppression of Skp2 in pancreatic cancer cells (52). Caffeic acid phenethyl ester suppressed cell proliferation and arrested the cell cycle through inactivation of Skp2 in prostate cancer cells (53). Notably, multiple natural agents have been characterized as Skp2 inhibitors (53-56). Flavokawain A (FKA) selectively inhibited Skp2 in a proteasome-dependent manner in prostate cancer (57). Quercetin, curcumin and lycopene enhanced cell cycle arrest via the targeting of Skp2 expression in breast cancer cells (54). Moreover, curcumin was validated to regulate the PI3K/Akt-SKP2-Cip/Kips pathway in breast cancer cells $(55,56)$. Furthermore, curcumin inhibited tumorigenesis via the downregulation of Skp2 in glioma cells (58). 15,16-Dihydrotanshinone I (DHTI) has been found to inhibit cell proliferation and migration, induce cell apoptosis and G1 phase arrest partly through the suppression of cell cycle regulators including Skp2 in OS cells (59). Li et al found that saurolactam inhibited proliferation, migration and invasion of human OS cells in part through the inactivation of Skp2 and pAkt (60). Collectively, Skp2 may be a potential therapeutic target for the treatment of OS.

\section{References}

1. Anderson ME: Update on survival in osteosarcoma. Orthop Clin North Am 47: 283-292, 2016.

2. Siegel RL, Miller KD and Jemal A: Cancer statistics, 2016. CA Cancer J Clin 66: 7-30, 2016.

3. Vos HI, Coenen MJ, Guchelaar HJ and Te Loo DM: The role of pharmacogenetics in the treatment of osteosarcoma. Drug Discov Today 21: 1775-1786, 2016.

4. Kushlinskii NE, Fridman MV and Braga EA: Molecular mechanisms and microRNAs in osteosarcoma pathogenesis Biochemistry 81: 315-328, 2016.

5. Li C, Cong Y, Liu X, Zhou X, Zhou G, Lu M, Shi X and Wu S: The progress of molecular diagnostics of osteosarcoma. Front Biosci 21: 20-30, 2016.

6. Tao J, Jiang MM, Jiang L, Salvo JS, Zeng HC, Dawson B, Bertin TK, Rao PH, Chen R, Donehower LA, et al: Notch activation as a driver of osteogenic sarcoma. Cancer Cell 26: 390-401, 2014

7. Carrano AC, Eytan E, Hershko A and Pagano M: SKP2 is required for ubiquitin-mediated degradation of the $\mathrm{CDK}$ inhibitor p27. Nat Cell Biol 1: 193-199, 1999.

8. Tsvetkov LM, Yeh KH, Lee SJ, Sun H and Zhang H: p27 $7^{\text {Kipl }}$ ubiquitination and degradation is regulated by the $\mathrm{SCF}^{\mathrm{skp} 2}$ complex through phosphorylated Thr187 in p27. Curr Biol 9: 661-664, 1999.
9. Yu ZK, Gervais JL and Zhang H: Human CUL-1 associates with the SKP1/SKP2 complex and regulates $\mathrm{p} 21^{\mathrm{CIP} / / \mathrm{WAF} 1}$ and cyclin D proteins. Proc Natl Acad Sci USA 95: 11324-11329, 1998.

10. Kamura T, Hara T, Kotoshiba S, Yada M, Ishida N, Imaki H, Hatakeyama S, Nakayama K and Nakayama KI: Degradation of $\mathrm{p} 57^{\text {Kip } 2}$ mediated by $\mathrm{SCF}^{\mathrm{Skp} 2}$-dependent ubiquitylation. Proc Natl Acad Sci USA 100: 10231-10236, 2003.

11. Huang H, Regan KM, Wang F, Wang D, Smith DI, van Deursen JM and Tindall DJ: Skp2 inhibits FOXO1 in tumor suppression through ubiquitin-mediated degradation. Proc Natl Acad Sci USA 102: 1649-1654, 2005.

12. Wang H, Cui J, Bauzon F and Zhu L: A comparison between Skp2 and FOXO1 for their cytoplasmic localization by Akt1. Cell Cycle 9: 1021-1022, 2010.

13. Nakayama K, Nagahama H, Minamishima YA, Matsumoto $M$, Nakamichi I, Kitagawa K, Shirane M, Tsunematsu R, Tsukiyama T, Ishida N, et al: Targeted disruption of $S k p 2$ results in accumulation of cyclin E and $\mathrm{p} 27^{K i p l}$, polyploidy and centrosome overduplication. EMBO J 19: 2069-2081, 2000.

14. Kratzat S, Nikolova V, Miething C, Hoellein A, Schoeffmann S, Gorka O, Pietschmann E, Illert AL, Ruland J, Peschel C, et al: Cks1 is required for tumor cell proliferation but not sufficient to induce hematopoietic malignancies. PLoS One 7: e37433, 2012.

15. Agarwal A, Bumm TG, Corbin AS, O'Hare T, Loriaux M, VanDyke J, Willis SG, Deininger J, Nakayama KI, Druker BJ, et al: Absence of SKP2 expression attenuates BCR-ABL-induced myeloproliferative disease. Blood 112: 1960-1970, 2008.

16. Nakayama K, Nagahama H, Minamishima YA, Miyake S, Ishida $N$, Hatakeyama $S$, Kitagawa $M$, Iemura $S$, Natsume $T$ and Nakayama KI: Skp2-mediated degradation of p27 regulates progression into mitosis. Dev Cell 6: 661-672, 2004.

17. Minamishima YA, Nakayama K and Nakayama K: Recovery of liver mass without proliferation of hepatocytes after partial hepatectomy in Skp2-deficient mice. Cancer Res 62: 995-999, 2002.

18. Chander H, Halpern M, Resnick-Silverman L, Manfredi JJ and Germain D: Skp2B attenuates p53 function by inhibiting prohibitin. EMBO Rep 11: 220-225, 2010.

19. Shim EH, Johnson L, Noh HL, Kim YJ, Sun H, Zeiss C and Zhang H: Expression of the F-box protein SKP2 induces hyperplasia, dysplasia, and low-grade carcinoma in the mouse prostate. Cancer Res 63: 1583-1588, 2003.

20. Sistrunk C, Kim SH, Wang X, Lee SH, Kim Y, Macias E and Rodriguez-Puebla ML: Skp2 deficiency inhibits chemical skin tumorigenesis independent of $\mathrm{p} 27^{\mathrm{Kipl}}$ accumulation. Am J Pathol 182: 1854-1864, 2013

21. Pagano M: Control of DNA synthesis and mitosis by the Skp2-p27-Cdk1/2 axis. Mol Cell 14: 414-416, 2004.

22. Kullmann MK, Grubbauer C, Goetsch K, Jäkel H, Podmirseg SR, Trockenbacher A, Ploner C, Cato AC, Weiss C, Kofler R, et al: The p27-Skp2 axis mediates glucocorticoid-induced cell cycle arrest in T-lymphoma cells. Cell Cycle 12: 2625-2635, 2013.

23. Lim MS, Adamson A, Lin Z, Perez-Ordonez B, Jordan RC, Tripp S, Perkins SL and Elenitoba-Johnson KS: Expression of Skp2, a $227^{\mathrm{Kip} 1}$ ubiquitin ligase, in malignant lymphoma: Correlation with $\mathrm{p} 27^{\mathrm{Kip} 1}$ and proliferation index. Blood 100: 2950-2956, 2002.

24. Schüler S, Diersch S, Hamacher R, Schmid RM, Saur D and Schneider G: SKP2 confers resistance of pancreatic cancer cells towards TRAIL-induced apoptosis. Int J Oncol 38: 219-225, 2011.

25. Chan CH, Lee SW, Wang J and Lin HK: Regulation of Skp2 expression and activity and its role in cancer progression. Sci World J 10: 1001-1015, 2010.

26. Hulit J, Lee RJ, Li Z, Wang C, Katiyar S, Yang J, Quong AA, Wu K, Albanese C, Russell R, et al: p2 $7^{\text {KipI }}$ repression of ErbB2-induced mammary tumor growth in transgenic mice involves Skp2 and Wnt/beta-catenin signaling. Cancer Res 66: 8529-8541, 2006.

27. Fujita T, Liu W, Doihara H, Date H and Wan Y: Dissection of the APC ${ }^{\text {Cdh1 }}$-Skp2 cascade in breast cancer. Clin Cancer Res 14: 1966-1975, 2008

28. Voduc D, Nielsen TO, Cheang MC and Foulkes WD: The combination of high cyclin E and Skp2 expression in breast cancer is associated with a poor prognosis and the basal phenotype. Hum Pathol 39: 1431-1437, 2008

29. Liu J, Wei XL, Huang WH, Chen CF, Bai JW and Zhang GJ: Cytoplasmic Skp2 expression is associated with p-Akt1 and predicts poor prognosis in human breast carcinomas. PLoS One 7: e52675, 2012. 
30. Wei S, Chu PC, Chuang HC, Hung WC, Kulp SK and Chen CS Targeting the oncogenic E3 ligase Skp2 in prostate and breast cancer cells with a novel energy restriction-mimetic agent. PLoS One 7: e47298, 2012.

31. Zhao H, Bauzon F, Fu H, Lu Z, Cui J, Nakayama K, Nakayama KI Locker J and Zhu L: Skp2 deletion unmasks a p27 safeguard that blocks tumorigenesis in the absence of pRb and p53 tumor suppressors. Cancer Cell 24: 645-659, 2013.

32. Masuda TA, Inoue H, Sonoda H, Mine S, Yoshikawa Y, Nakayama K, Nakayama K and Mori M: Clinical and biological significance of $S$-phase kinase-associated protein 2 (Skp2) gene expression in gastric carcinoma: Modulation of malignant phenotype by Skp2 overexpression, possibly via p27 proteolysis. Cancer Res 62: 3819-3825, 2002.

33. Benevenuto-de-Andrade BA, León JE, Carlos R, DelgadoAzañero W, Mosqueda-Taylor A and Paes-de-Almeida O Immunohistochemical expression of Skp2 protein in oral nevi and melanoma. Med Oral Patol Oral Cir Bucal 18: e388-e391, 2013.

34. Qu X, Shen L, Zheng Y, Cui Y, Feng Z, Liu F and Liu J: A signal transduction pathway from TGF- $\beta 1$ to SKP2 via Akt1 and c-Myc and its correlation with progression in human melanoma. J Invest Dermatol 134: 159-167, 2014

35. Chen G, Cheng Y, Zhang Z, Martinka M and Li G: Cytoplasmic Skp2 expression is increased in human melanoma and correlated with patient survival. PLoS One 6: e17578, 2011

36. Lu M, Ma J, Xue W, Cheng C, Wang Y, Zhao Y, Ke Q, Liu H, Liu Y, Li P, et al: The expression and prognosis of FOXO3a and Skp2 in human hepatocellular carcinoma. Pathol Oncol Res 15: 679-687, 2009

37. Xu HM, Liang Y, Chen Q, Wu QN, Guo YM, Shen GP, Zhang RH, He ZW, Zeng YX, Xie FY, et al: Correlation of Skp2 overexpression to prognosis of patients with nasopharyngeal carcinoma from South China. Chin J Cancer 30: 204-212, 2011.

38. Fang FM, Chien CY, Li CF, Shiu WY, Chen CH and Huang HY: Effect of $S$ phase kinase-associated protein 2 expression on distant metastasis and survival in nasopharyngeal carcinoma patients. Int J Radiat Oncol Biol Phys 73: 202-207, 2009.

39. Liao QD, Zhong D and Chen Q: Protein expression of Skp2 in osteosarcoma and its relation with prognosis. Zhong Nan Da Xue Xue Bao Yi Xue Ban 33: 606-611, 2008 (In Chinese).

40. Xu D, Li CF, Zhang X, Gong Z, Chan CH, Lee SW, Jin G, Rezaeian AH, Han F, Wang J, et al: Skp2-macroH2A1-CDK8 axis orchestrates $\mathrm{G} 2 / \mathrm{M}$ transition and tumorigenesis. Nat Commun 6: 6641, 2015 .

41. Lee SW, Li CF, Jin G, Cai Z, Han F, Chan CH, Yang WL, Li BK, Rezaeian AH, Li HY, et al: Skp2-dependent ubiquitination and activation of LKB1 is essential for cancer cell survival under energy stress. Mol Cell 57: 1022-1033, 2015.

42. Wang IC, Chen YJ, Hughes D, Petrovic V, Major ML, Park HJ, Tan Y, Ackerson T and Costa RH: Forkhead box M1 regulates the transcriptional network of genes essential for mitotic progression and genes encoding the SCF (Skp2-Cks1) ubiquitin ligase. Mol Cell Biol 25: 10875-10894, 2005.

43. Tanaka M, Setoguchi T, Hirotsu M, Gao H, Sasaki H, Matsunoshita Y and Komiya S: Inhibition of Notch pathway prevents osteosarcoma growth by cell cycle regulation. Br J Cancer 100: 1957-1965, 2009.

44. Hirotsu M, Setoguchi T, Sasaki H, Matsunoshita Y, Gao H, Nagao H, Kunigou O and Komiya S: Smoothened as a new therapeutic target for human osteosarcoma. Mol Cancer 9: 5, 2010.

45. Nagao H, Ijiri K, Hirotsu M, Ishidou Y, Yamamoto T, Nagano S, Takizawa T, Nakashima K, Komiya S and Setoguchi T: Role of GLI2 in the growth of human osteosarcoma. J Pathol 224: 169-179, 2011.
46. Gao D, Inuzuka H, Tseng A, Chin RY, Toker A and Wei W: Phosphorylation by Akt1 promotes cytoplasmic localization of Skp2 and impairs APCCdh1-mediated Skp2 destruction. Nat Cell Biol 11: 397-408, 2009.

47. Lin HK, Wang G, Chen Z, Teruya-Feldstein J, Liu Y, Chan CH, Yang WL, Erdjument-Bromage H, Nakayama KI, Nimer S, et al: Phosphorylation-dependent regulation of cytosolic localization and oncogenic function of Skp2 by Akt/PKB. Nat Cell Biol 11: 420-432, 2009.

48. Zhang H: Skip the nucleus, AKT drives Skp2 and FOXO1 to the same place? Cell Cycle 9: 868-869, 2010.

49. Chan CH, Li CF, Yang WL, Gao Y, Lee SW, Feng Z, Huang HY, Tsai KK, Flores LG, Shao Y, et al: The Skp2-SCF E3 ligase regulates Akt ubiquitination, glycolysis, herceptin sensitivity, and tumorigenesis. Cell 149: 1098-1111, 2012.

50. Singh R, Sran A, Carroll DC, Huang J, Tsvetkov L, Zhou X, Sheung J, McLaughlin J, Issakani SD, Payan DG, et al: Developing structure-activity relationships from an HTS hit for inhibition of the Cks1-Skp2 protein-protein interaction. Bioorg Med Chem Lett 25: 5199-5202, 2015.

51. Oh M, Lee JH, Moon H, Hyun YJ and Lim HS: A chemical inhibitor of the Skp2/p300 interaction that promotes $\mathrm{p} 53$-mediated apoptosis. Angew Chem Int Ed Engl 55: 602-606, 2016

52. Gao JK, Wang LX, Long B, Ye XT, Su JN, Yin XY, Zhou XX and Wang ZW: Arsenic trioxide inhibits cell growth and invasion via down-regulation of Skp2 in pancreatic cancer cells. Asian Pac J Cancer Prev 16: 3805-3810, 2015.

53. Lin HP, Lin CY, Huo C, Hsiao PH, Su LC, Jiang SS, Chan TM, Chang CH, Chen LT, Kung HJ, et al: Caffeic acid phenethyl ester induced cell cycle arrest and growth inhibition in androgen-independent prostate cancer cells via regulation of Skp2, p53, p21Cip1 and p27Kip1. Oncotarget 6: 6684-6707, 2015.

54. Huang HC, Lin CL and Lin JK: 1,2,3,4,6-penta- $O$-galloyl- $\beta$ $\mathrm{D}$-glucose, quercetin, curcumin and lycopene induce cell-cycle arrest in MDA-MB-231 and BT474 cells through downregulation of Skp2 protein. J Agric Food Chem 59: 6765-6775, 2011.

55. Jia T, Zhang L, Duan Y, Zhang M, Wang G, Zhang J and Zhao Z: The differential susceptibilities of MCF-7 and MDA-MB-231 cells to the cytotoxic effects of curcumin are associated with the PI3K/Akt-SKP2-Cip/Kips pathway. Cancer Cell Int 14: 126, 2014.

56. Sun SH, Huang HC, Huang C and Lin JK: Cycle arrest and apoptosis in MDA-MB-231/Her2 cells induced by curcumin. Eur J Pharmacol 690: 22-30, 2012.

57. Li X, Yokoyama NN, Zhang S, Ding L, Liu HM, Lilly MB, Mercola D and Zi X: Flavokawain A induces deNEDDylation and Skp2 degradation leading to inhibition of tumorigenesis and cancer progression in the TRAMP transgenic mouse model. Oncotarget 6: 41809-41824, 2015.

58. Wang L, Ye X, Cai X, Su J, Ma R, Yin X, Zhou X, Li H and Wang Z: Curcumin suppresses cell growth and invasion and induces apoptosis by down-regulation of Skp2 pathway in glioma cells. Oncotarget 6: 18027-18037, 2015.

59. Chen X, Li Q, He Y, Du H, Zhan Z, Zhao H, Shi J, Ye Q and Hu J: 15,16-dihydrotanshinone I induces apoptosis and inhibits the proliferation, migration of human osteosarcoma cell line 143B in vitro. Anticancer Agents Med Chem 15: 1, 2015.

60. Li Z, Liu H, Li B, Zhang Y and Piao C: Saurolactam inhibits proliferation, migration, and invasion of human osteosarcoma cells. Cell Biochem Biophys 72: 719-726, 2015. 